\title{
Analysis of Pure Bending Vertical Deflection of Improved Composite Box Girders with Corrugated Steel Webs
}

\author{
Chi Ma $\mathbb{D}^{1},{ }^{1}$ Shi-zhong Liu, ${ }^{1}$ Jin Di, ${ }^{2}$ and Rui-jie Zhang ${ }^{3}$ \\ ${ }^{1}$ College of Civil Engineering, Lanzhou Jiao Tong University, Lan zhou 730070, China \\ ${ }^{2}$ School of Civil Engineering, Chongqing University, Chongqing 400045, China \\ ${ }^{3}$ State Key Laboratory of Mountain Bridge and Tunnel Engineering, Chongqing Jiao Tong University, Chongqing 400074, China
}

Correspondence should be addressed to Chi Ma; 308329771@qq.com

Received 30 December 2020; Revised 11 March 2021; Accepted 17 March 2021; Published 30 March 2021

Academic Editor: Lingzhi Li

Copyright (c) 2021 Chi Ma et al. This is an open access article distributed under the Creative Commons Attribution License, which permits unrestricted use, distribution, and reproduction in any medium, provided the original work is properly cited.

\begin{abstract}
Steel bottom plates are applied as replacements for the concrete bottom plates in order to reduce the dead weight of the composite box girders with corrugated steel webs and steel bottom plates (CSWSB). Due to the change in the material, the previous analytical calculation methods of vertical deflection of composite box girders with corrugated steel webs (CSWs) cannot be directly applied to the improved composite box girders. The shear lag warpage displacement function was derived based on the shear deformation laws of the upper flange and the bottom plates of the improved composite box girders. The equations for the calculation of the shear deformation and the additional deflection due to the shear lag of continuous and simply supported composite box girders with CSWSB under concentrated and uniformly distribution loads were derived by considering the double effects of the shear lag and the shear deformations of the top and the bottom plates with different elastic moduli. The analytical solutions of the vertical deflection of the improved composite box girders include the theory of the bending deflection of elementary beams, shear deformation of CSWs, and the additional deflection caused by the shear lag. Based on the theoretical derivation, an analytical solution method was established and the obtained vertical deflection analytical solutions were compared with the finite element method (FEM) calculation results and the experimental values. The analytical equations of vertical deflection under the two supporting conditions and the two load cases have verified the analyses and the comparisons. Further, the additional deflections due to the shear lag and the shear deformation are found to be less than $2 \%$ and $34 \%$ of the total deflection values, respectively. Moreover, under uniform distributed load conditions, the deflection value was found to be higher than that of the under concentrated load condition. It was also found that the ratio of the deflection caused by the shear lag or the shear deformation to the total deflection decreased gradually with the increase in the span width ratio. When the value of the span width ratio of a single box and single chamber composite box girder with CSWSB was equal to or greater than 8 , the deflections caused by the shear lag and the shear deformation could be ignored.
\end{abstract}

\section{Introduction}

The steel bottom plates are used instead of the concrete bottom plates in order to reduce the dead weight of the traditional composite box girders with corrugated steel webs. In this work, a type of improved composite box girders was developed, which is referred to as composite box girders with corrugated steel webs and steel bottom plates (CSWSB). For the traditional composite box girder bridges with corrugated steel webs (CSWs) that are exposed to bending loads, the shear deformation caused by the shear force of
CSW significantly affects girder deflections $[1,2]$. From the literature, it is observed that many researchers had focused on the shear buckling strengths of CSWs and the additional lateral bending moments of flange plates under shear force [3-5]. Jiang et al. [6] analyzed the influence of the shear deformation of composite box girders with CSW on structural deflections. Guo et al. $[7,8]$ introduced the web shear deformation angle function and derived the analytical solution of the simply supported beam under uniform load and concentrated load in the midspan of the end restraint. By considering the shear deformation and by introducing 
the angle function of web shear deformation, the deformation calculation formula was derived for the composite beam with CSWs under different boundary conditions and loads. Further, according to the principle of deformation equivalent, the important influence parameters were identified and the effective stiffness method for the composite box girders with CSWs was proposed. Hong et al. [9] developed the calculation equations for the deflection curves of the composite box girders with CSW by considering the shear deformation using the initial parameter equation and analyzed the deflections of the composite beams with CSW under three typical loading modes, i.e., concentrated load at middle span, symmetrical load at two points, and uniformly distributed load. Qing et al. $[10,11]$ found that the shear lag reduced the bending stiffness of the traditional composite box girder sections and increased the deflections of the composite bridge structures. Dong et al. [12] investigated the deflection calculation equation of the composite box girders with CSW under different loads and boundary conditions using the energy variation method. The influence of various factors on the deflections of the box girders with CSW was analyzed. Based on the experimental model of CSWS composite box girder bridge, Wei et al. $[13,14]$ derived the longitudinal displacement functions and the deflection calculation equations of the composite box girders with CSW and determined the main influential factors on deflections under different width span ratios and corrugated steel web heights. Zhou et al. [15] analyzed the shear lag effect of nonprismatic composite box girder with corrugated steel webs in the elastic stage. Chen et al. [16-18] proposed a new type of bridge composite box girder structure with upper flange and lower flange of concrete-filled prestressed pipe. Through the scale model of concrete-filled steel tube, the bending performance and shear lag effect of the simply supported composite box girder with corrugated steel web truss were studied, and its deflection, strain, and bending capacity were studied. Zhou et al. [19] derived the general formula of shear stress of nonuniform box girder with corrugated steel webs in the elastic stage from the static equilibrium condition and the equivalent law of shear stress of infinitesimal section. From the literature, it is found that the previous studies did not study the deflection of CSWSB beam bridges, and there is no simple formula to estimate their deflection under static load. Moreover, there are only a few experimental research studies on the overall performance of the CSWSB beam [20,21]. A simple and accurate formula for calculating the deflection of this kind of beam bridge is very desirable.

Further, the existing literature has made some achievements on the deflection calculation of traditional composite box girders with CSWs, but the research on improved composite box girders with corrugated steel webs is relatively scarce. Due to the change in the material, the previous analytical calculation methods of vertical deflection of the composite box girders with CSWs cannot be directly applied to the improved composite box girders. Therefore, this work is focused on improving the analytical calculation of deflection of the composite box girders with CSWSB. Initially, a shear lag warpage displacement function was derived based on the shear deformation laws of the upper flange and the bottom plates of improved composite box girders. Then, by considering the double effects of the shear lag, the shear deformation, and the different moduli of the upper flange and the bottom plates, the governing differential equation and the boundary conditions of the composite box girders with CSWSB were derived. Further, the deflection calculation equations due to the shear lag and the shear deformation of the continuous and simply supported composite box girders with CSWSB under different loads were obtained. The obtained results were compared with the simulation analysis results that were obtained from the ANSYS finite element analysis and the experimental data. Finally, the variation trends of the contributions of the shear lag and the shear deformation to total deflection with span width ratio were analyzed.

\section{Derivation of the Shear Lag Displacement Function for the Composite Box Girders with CSWSB}

The shear lag effect is essentially generated by the shear deformation. Therefore, a reasonable shear lag longitudinal displacement function for composite box girders with CSWSB could be derived based on the shear deformation laws of the concrete upper flange and the steel bottom plates. For the composite box girder with CSWSB section shown in Figure 1, the calculation equation of the bending shear flow on the composite box girder section due to shear force [22] was as shown in the following equation:

$$
\begin{aligned}
q(s) & =-\frac{Q(x)}{I_{y}} S_{y}+\frac{\left(Q(x) / I_{y}\right) \oint\left(S_{y} / t\right) \mathrm{d} s}{\oint(1 / t) \mathrm{d} s} \\
& =-\frac{Q(x)}{I_{y}}\left(S_{y}-\frac{\oint\left(S_{y} / t\right) \mathrm{d} s}{\oint(1 / t) \mathrm{d} s}\right) .
\end{aligned}
$$

In equation (1), $I_{y}$ is the sectional moment of the inertia of composite box girder with CSWSB and $S_{y}$ is static area moment defined as $S_{y}=\int_{0}^{s} z t \mathrm{~d} s$. Further, $t$ is substituted by $t_{1}$ and $t_{2}$ for the upper flange plate and the bottom flange plate, respectively, where $t_{1}$ and $t_{2}$ are the thicknesses of the upper flange and bottom plate, respectively. $s$ refers to the coordinate of the surrounding points where the origin and the incision coincide.

The concrete upper flange plate was divided into top and cantilever plates. By considering the top plate as an example, the cut was set at the center (0) of the top plate, and the second term in equation (1) was taken as zero. Then, its bending shear force flow was obtained as shown in the following equation: 


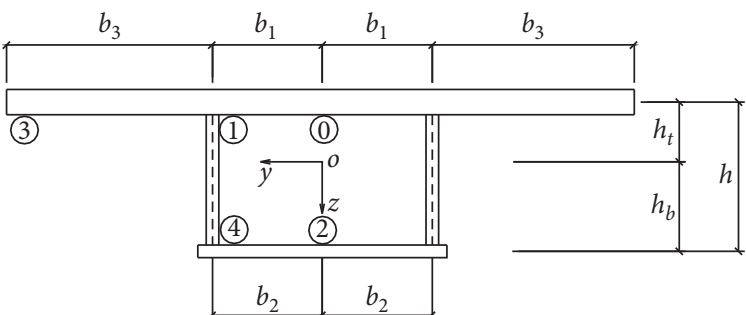

FIgURE 1: Sectional diagram of a composite box girder with CSWSB.

$$
q(s)=-\frac{Q(x)}{I_{y}} S_{y}=\frac{Q(x)}{I_{y}} h_{t} t_{1} s .
$$

Further, the in-plane shear strain of the roof $\gamma(s)$ was obtained as shown in the following equation:

$$
\gamma(s)=\frac{\partial \mathrm{u}}{\partial s}+\frac{\partial v}{\partial s} \approx \frac{\partial \mathrm{u}}{\partial s}=\frac{q(s)}{G_{c} t}=\frac{Q(x)}{G_{c} I_{y}} h_{t} s .
$$

In equation (3), uand $v$ are the longitudinal and the lateral displacements of the roof, respectively, and $G_{c}$ is the shear modulus of the concrete. According to elasticity mechanics, $v$ is very small and can be ignored.

By integrating equation (3), the following equation was obtained:

$$
u(s, x)-u_{0}(x)=\frac{Q(x) h_{t}}{2 G_{c} I_{y}} s^{2}
$$

Equation (4) gave the longitudinal displacement of the concrete roof of the composite box girder, where $u_{0}(x)$ is the longitudinal displacement of the incision.

Longitudinal displacement $u_{1}(x)$ at junction (1) was obtained as given in the following equation:

$$
u_{1}(x)=\frac{Q(x) h_{t}}{2 G_{c} I_{y}} b_{1}^{2}+u_{0}(x) .
$$

Then, the maximum longitudinal displacement difference function $\xi_{1}(x)$ of the composite box girder roof was obtained as follows:

$$
\xi_{1}(x)=u_{1}(x)-u_{0}(x)=\frac{Q(x) h_{t}}{2 G_{c} I_{y}} b_{1}^{2} .
$$

The horizontal position of any point in the middle of the roof was stated by y coordinate which was obtained from equation (4) is shown in the following:

$$
u(x, y)=\frac{Q(x) h_{t}}{2 G_{c} I_{y}} y^{2}+u_{0}(x)
$$

By substituting equation (6) into equation (7), the longitudinal displacement function of the roof was derived as follows:

$$
\begin{aligned}
u_{t}(x, y) & =\frac{Q(x) h_{t}}{2 G_{c} I_{y}} y^{2}+u_{1}(x)-\frac{Q(x) h_{t}}{2 G_{c} I_{y}} b_{1}^{2} \\
& =u_{1}(x)-\left(1-\frac{y^{2}}{b_{1}^{2}}\right) \xi_{1}(x) .
\end{aligned}
$$

Similarly, for the midpoint (2) of the steel bottom plate and the endpoint (3) of the concrete cantilever plate, the longitudinal displacement functions of the steel bottom and the cantilever plates were obtained as follows:

$$
\begin{aligned}
& u_{b}(x, y)=u_{4}(x)-\left(1-\frac{y^{2}}{b_{2}^{2}}\right) \xi_{2}(x), \\
& u_{x}(x, y)=u_{1}(x)-\left(1-\frac{\left(b_{1}+b_{3}-y\right)^{2}}{b_{3}^{2}}\right) \xi_{3}(x) .
\end{aligned}
$$

In equations (9) and (10), $\xi_{2}(x)$ and $\xi_{3}(x)$ are the displacement difference functions of the steel bottom and the concrete cantilever plates, respectively, which are defined as $\xi_{2}(x)=\left(Q(x) h_{t} / 2 G_{s} I_{y}\right) b_{2}^{2}$ and $\xi_{3}(x)=\left(Q(x) h_{t} / 2 G_{c}\right.$ $\left.I_{y}\right) b_{3}^{2}$. $G_{s}$ is the steel shear modulus, and $u_{4}(x)$ is the longitudinal displacement of the junction point (4) between the steel bottom and the steel web plates.

Further, it was assumed that web deformation on the cross-section of the composite box girder conformed to the "quasi plane section assumption" as proposed by Qing et al [10]. The longitudinal displacement functions at junctions (1) and (4) were obtained as follows:

$$
\begin{aligned}
& u_{1}(x)=-h_{t}\left(\frac{\mathrm{d} w(x)}{\mathrm{d} x}-\gamma(x)\right)=-h_{t} \theta(x), \\
& u_{4}(x)=-h_{b}\left(\frac{\mathrm{d} w(x)}{\mathrm{d} x}-\gamma(x)\right)=h_{b} \theta(x) .
\end{aligned}
$$

In equations (11) and (12), $w(x)$ is the vertical displacement, $\gamma(x)$ is the shear strain, and $\theta(x)$ is the angle of the composite box girder with CSWSB after the deformation of CSW.

By assuming $\xi(x)=\left(Q(x) / 2 G_{c} I_{y}\right) b_{1}^{2}$, the longitudinal displacement function of the unified composite box girder with CSWSB was obtained as follows: 


$$
\begin{cases}u_{t}(x, y, z)=-h_{t} \theta(x)-h_{t}\left(1-\frac{y^{2}}{b_{1}^{2}}\right) \xi(x), & \text { top plate, } \\ u_{x}(x, y, z)=-h_{t} \theta(x)-h_{t}\left[1-\frac{\left(b_{1}+b_{3}-y\right)^{2}}{b_{3}^{2}}\right]\left(\frac{b_{3}}{b_{1}}\right)^{2} \xi(x), & \text { cantilever plate } \\ u_{b}(x, y, z)=h_{b} \theta(x)+h_{b}\left(1-\frac{y^{2}}{b_{2}^{2}}\right)\left(\frac{b_{2}}{b_{1}}\right)^{2}\left(\frac{G_{c}}{G_{s}}\right) \xi(x), & \text { bottom plate, } \\ u_{w}(x, y, z)=h \theta(x), & \text { web. }\end{cases}
$$

In equation (13), $h$ denotes the vertical coordinates of each point of the section when the neutral axis is the $y$ axis. Further, the longitudinal displacement $u(x, y, z)$ of each plate in the composite box girder consisted of the bending longitudinal $u_{e}(x, z)$ and the shear lag longitudinal warping $u_{w}(x, y, z)$ displacements that were calculated using the elementary beam theory and are given as follows: $u(x, y, z)=u_{e}(x, z)+u_{w}(x, y, z)=h \theta(x)+f(y, z) \xi(x)$.

In equation (14), the shear lag warping displacement function $f(y, z)$ is applied to the composite box girder bridge as follows:

$$
f(y, z)= \begin{cases}f_{1}(y, z)=-h_{t}\left(1-\frac{y^{2}}{b_{1}^{2}}\right)+d, & \text { top plate, } \\ f_{2}(y, z)=-h{ }_{t}\left[1-\frac{\left(b_{1}+b_{3}-y\right)^{2}}{b_{3}^{2}}\right]\left(\frac{b_{3}}{b_{1}}\right)^{2}+d, & \text { cantilever plate } \\ f_{3}(y, z)=h_{b}\left(1-\frac{y^{2}}{b_{2}^{2}}\right)\left(\frac{b_{2}}{b_{1}}\right)^{2}\left(\frac{G_{c}}{G_{s}}\right)+d, & \text { bottom plate, } \\ f_{4}(y, z)=d, & \text { web. }\end{cases}
$$

In equation (15), $d$ is additional axial force-displacement which satisfies the axial force self-balance of the whole section. According to the equilibrium condition of zero axial force of the cross-section $\int f(y, z) \mathrm{d} A=0$, the following condition had to be applied:

$$
d=\frac{2 h_{t}}{3 A}\left[A_{t}+A_{c}\left(\frac{b_{3}}{b_{1}}\right)^{2}-A_{b} \frac{h_{b}}{h_{t}}\left(\frac{b_{2}}{b_{1}}\right)^{2}\left(\frac{G_{c}}{G_{s}}\right)\right] .
$$

In equation (16), $A$ is the area of the whole section and is defined as $A=A_{t}+A_{c}+A_{b}$, where $A_{t}$ is half of the crosssectional area of the roof calculated as $A_{t}=\mathrm{t}_{1} b_{1}, A_{c}$ is half of the sectional area of the cantilever plate defined as $A_{c}=t_{1} b_{3}$, and $A_{b}$ is half of the cross-sectional area of the base plate as $A_{b}=t_{2} b_{2}$.

Samanta et al. calculated the shear modulus $G_{\mathrm{e}}$ of CSW [23], which had to be modified as

$$
G_{\mathrm{e}}=\frac{\left(L_{1}+L_{2}\right)}{\left(L_{1}+L_{3}\right)} G_{\mathrm{s}} \text {. }
$$

In equation (17), $L_{1}, L_{2}$, and $L_{3}$ represent the geometric dimensions, as shown in Figure 2.

\section{Establishment of the Differential Equation and the Solution of the Deflection Expression}

In this work, it was assumed that there was no slippage between the $U$-type beam with CSW and the concrete upper flange plate, and both of them were considered to be ideal elastic bodies. Further, the composite steel beam and the concrete upper flange plate were in accordance with the quasi plane section assumption, and the CSW was considered as $\gamma_{x z}$. Moreover, it was also assumed that, for the steel beam bottom and the concrete upper flange plates, $\varepsilon_{y}=\varepsilon_{z}=\gamma_{x z}=\gamma_{y z}=0$, except $\varepsilon_{x}$ and $\gamma_{x y}$.

The potential energy of the composite box girder with CSWSB with a single box and a single cell was obtained as follows: 


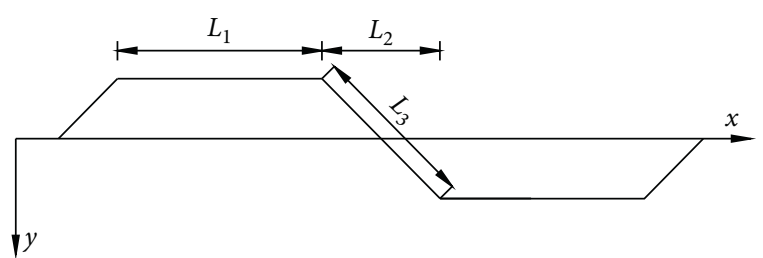

Figure 2: Geometry of the corrugated steel webs.

$$
W=-\int_{0}^{l} M(x) \theta^{\prime}(x) \mathrm{d} x+\int_{0}^{l} Q(x) \gamma(x) \mathrm{d} x .
$$

The shear modulus of the CSW was modified according to equation (17). The shear strain energy of the composite box girder web was obtained as shown in the following equation:fd19

$$
\begin{aligned}
V_{\omega} & =2\left\{\frac{1}{2} \int_{0}^{l} \int_{0}^{h_{w}} t_{w} G_{e} \gamma^{2} \mathrm{~d} z \mathrm{~d} x\right\}=\int_{0}^{l} h_{w} t_{w} G_{e} \gamma^{2} \mathrm{~d} x \\
& =\int_{0}^{l} A_{w} G_{e} \gamma^{2} \mathrm{~d} x=\int_{0}^{l} \mathrm{Q}(x) \gamma(x) \mathrm{d} x .
\end{aligned}
$$

In equation (19), $A_{w}$ is the cross-section area of the CSW and $\gamma(x)=\left(Q(x) / G_{e} A_{w}\right)$.

The strain energies of the top and the bottom plates of the composite box girder were obtained as follows:

$$
\begin{aligned}
V_{s u} & =V_{s u 1}+V_{s u 2}+V_{s b} \\
& =\frac{1}{2} \int_{0}^{l}\left[\Psi_{1} \xi^{2}(x)+\Psi_{2} \theta^{\prime 2}(x)-2 \Psi_{3} \theta^{\prime}(x) \xi^{\prime}(x)+\Psi_{4} \xi^{2}(x)\right] \mathrm{d} x .
\end{aligned}
$$

In equation (20), $E_{c}, G_{c}, E_{s}$, and $G_{s}$ denote the elastic and the shear moduli of the concrete and the steel. The subscripts $c$ and $s$ denote the concrete and steel, respectively.

$$
\begin{aligned}
\Psi_{1}= & E_{c} \int_{A_{t}} f_{1}^{2}(y, z) \mathrm{d} A+E_{c} \int_{A_{c}} f_{2}^{2}(y, z) \mathrm{d} A+E_{s} \int_{A_{b}} f_{3}^{2}(y, z) \mathrm{d} A, \\
\Psi_{2}= & E_{c} \int_{A_{t}} h_{t}^{2} \mathrm{~d} A+E_{c} \int_{A_{c}} h_{t}^{2} \mathrm{~d} A+E_{s} \int_{A_{b}} h_{b}^{2} \mathrm{~d} A, \\
\Psi_{3}= & E_{c} \int_{A_{t}} h_{t} f_{1}(y, z) \mathrm{d} A+E_{c} \int_{A_{c}} h_{t} f_{1}(y, z) \mathrm{d} A \\
& +E_{s} \int_{A_{b}} h_{b} f_{3}(y, z) \mathrm{d} A, \\
\Psi_{4}= & G_{c} \int_{A_{t}}\left[f_{1}^{\prime}(y, z)\right]^{2} \mathrm{~d} A+G_{c}\left[f_{2}^{\prime}(y, z)\right]^{2} \mathrm{~d} A \\
& +G_{s} \int_{A_{b}}\left[f_{3}^{\prime}(y, z)\right]^{2} \mathrm{~d} A .
\end{aligned}
$$

The total potential energy of the composite box girder with the CSWSB system was obtained as follows:

$$
\begin{aligned}
\Pi= & -W+V_{\omega}+V_{s u}=\frac{1}{2} \int_{0}^{l} \\
& \left(\Psi_{1} \xi^{\prime 2}(x)+\Psi_{2} \theta^{\prime 2}(x) 2 \Psi_{3} \theta^{\prime}(x) \xi^{\prime}(x)+\Psi_{4} \xi^{2}(x)\right) \mathrm{d} x \\
& +\int_{0}^{l} M(x) \theta^{\prime}(x) \mathrm{d} x .
\end{aligned}
$$

By holding the equation $\Sigma=(1 / 2)\left[\Psi_{1} \xi^{2}(x)+\Psi_{2} \theta^{\prime 2}\right.$ $\left.(x)-2 \Psi_{3} \theta^{\prime}(x) \xi^{\prime}(x)+\Psi_{4} \xi^{2}(x)\right]+M(x) \theta^{\prime}(x)$, the differential equation and the boundary conditions that were obtained from $\delta \Sigma=0$ were as follows:

$$
\left\{\begin{array}{l}
\Psi_{2} \theta^{\prime \prime}(x)-\Psi_{3} \xi^{\prime \prime}(x)+Q(x)=0, \\
\Psi_{4} \xi(x)-\Psi_{1} \xi^{\prime \prime}(x)+\Psi_{3} \theta^{\prime \prime}(x)=0, \\
{\left.\left[\Psi_{1} \xi^{\prime}(x)-\Psi_{3} \theta^{\prime}(x)\right] \delta \xi(x)\right|_{0} ^{l}=0,} \\
{\left.\left[\Psi_{2} \theta^{\prime}(x)-\Psi_{3} \xi^{\prime}(x)+M(x)\right] \delta \theta(x)\right|_{0} ^{l}=0 .}
\end{array}\right.
$$

Further, the shear lag differential equation was obtained as follows:

$$
\xi^{\prime \prime}(x)-k^{2} \xi(x)=-\bar{n} Q(x),
$$

where $\bar{n}=\Psi_{3} /\left(\Psi_{1} \Psi_{2}-\Psi_{3}^{2}\right)$ and $k^{2}=\Psi_{2} \Psi_{4} /\left(\Psi_{1} \Psi_{2}-\Psi_{3}^{2}\right)$.

The general solutions of differential equations were obtained as follows:

$$
\xi(x)=\bar{n}\left(C_{1} \operatorname{sh} k x+C_{2} \operatorname{ch} k x+D\right) .
$$

In equation (25), $D$ refers to a special solution related to the distribution of the shear force $Q(x)$ and $C_{1}$ and $C_{2}$ are determined by the boundary conditions.

From the expression $\theta(x)=(\mathrm{d} w(x) / \mathrm{d} x)-\gamma(x)=(\mathrm{d} w$ $(x) / \mathrm{d} x)-\left(\mathrm{Q}(x) / G_{e} A_{w}\right)$, the following equation was obtained.

$$
\theta^{\prime}(x)=w^{\prime \prime}(x)-\gamma^{\prime}(x)=-\frac{M(x)}{\Psi_{2}}+\frac{\Psi_{3}}{\Psi_{2}} \xi^{\prime}(x) .
$$

Further,

$w^{\prime \prime}(x)=-\left(M(x) / \Psi_{2}\right)+\left(\Psi_{3} / \Psi_{2}\right) \xi^{\prime}(x)+\left(Q(x) / G_{e} A_{w}\right)$ was obtained.

The deflection expression of the composite box girder with CSWSB was obtained by quadratic integral as follows:

$$
\begin{aligned}
w= & -\int\left[\int \frac{M(x)}{\Psi_{2}} \mathrm{~d} x\right] \mathrm{d} x-\int\left[\int \frac{\Psi_{3} \xi^{\prime}(x)}{\Psi_{2}} \mathrm{~d} x\right] \mathrm{d} x \\
& +\int\left[\int \frac{Q^{\prime}(x)}{G_{e} A_{w}} \mathrm{~d} x\right] \mathrm{d} x+C_{1} x+C_{2} .
\end{aligned}
$$

From equation (28), it was seen that the first term $w_{1}=$ $-\int\left[\int\left(M(x) / \Psi_{2}\right) \mathrm{d} x\right] \mathrm{d} x+C_{11} x+C_{12}$ was the equation used for calculating the deflection of the elementary beam theory.

The second term $w_{2}=-\int\left[\int\left(\Psi_{3} \xi^{\prime}(x) / \Psi_{2}\right) \mathrm{d} x\right] \mathrm{d} x+C_{21} x$ $+C_{22}$ calculated the additional deflection due to the shear lag effect. 
The third term $w_{3}=\int\left[\int\left(Q^{\prime}(x) / G_{e} A_{w}\right) \mathrm{d} x\right] \mathrm{d} x+C_{31} x+$ $C_{32}$ determined the deflection caused by the CSW shear deformation.

\section{Deflection Analysis of the Continuous and the Simply Supported Composite Box Girders with CSWSB under Different Loading Modes}

The deflection analysis of the continuous and the simply supported composite box girders with CSWSB under concentrated and uniformly distributed load conditions was carried out, and they are discussed as follows.

4.1. Deflections of Two Equal Span Continuous Composite Box Girders with CSWSB under Concentrated Load. Initially, for two-span continuous composite box girders with CSWSB with constant cross-sections, the total deflection due to concentrated load $P$ was applied in each span. Thereafter, the theoretical deflection of the primary beam $\mathrm{w}_{1}$, the deflections due to the shear lag effect $\mathrm{w}_{2}$, and the shear deformation $_{3}$ were obtained. The bearing reactions were obtained as $R_{A}=R_{E}=0.312 P$ and $R_{C}=1.376 P$. The schematic representation of two equal span continuous composite box girders with CSWSB under concentrated load is shown in Figure 3. By taking the left span as an example, the bending moment and the shear force equation were obtained as follows:

$$
\begin{aligned}
& \text { When } 0 \leq x \leq \frac{l}{2},\left\{\begin{array}{l}
M_{1}(x)=0.312 P x, \\
Q_{1}(x)=0.312 P,
\end{array}\right. \\
& \text { When } \frac{l}{2}<x \leq l,\left\{\begin{array}{l}
M_{2}(x)=0.312 P x-P\left(x-\frac{l}{2}\right), \\
Q_{2}(x)=-0.688 P .
\end{array}\right.
\end{aligned}
$$

(1) The deflection of the continuous composite box girders with CSWSB under the concentrated loads $w_{11}$ and $w_{12}$, under the boundary conditions: (1)

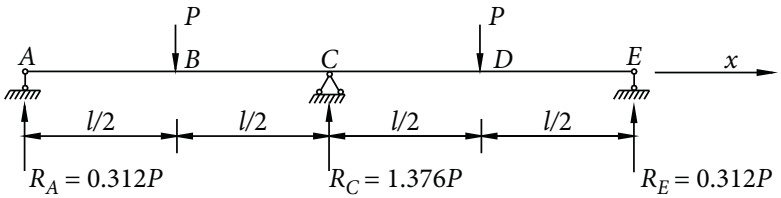

Figure 3: The schematic representation of two equal span continuous composite box girders with CSWSB under concentrated load condition.

when $x=0, \mathrm{w}_{11}=0$; (2) when $x=l / 2, w_{11}^{\prime}=w_{12}^{\prime} ;(3)$ when $x=l / 2, w_{11}=w_{12}$; and (4) when $x=l$, $w_{12}=0$, is deduced as shown in the following equations:

$$
\begin{aligned}
\text { When } 0 \leq x \leq \frac{l}{2}, w_{11}= & -\frac{0.312 P x^{3}}{6 \psi_{2}}+\frac{1.496}{48 \psi_{2}} P l^{2} x, \\
\text { When } \frac{l}{2}<x \leq l, w_{12}= & -\frac{0.312 P x^{3}}{6 \psi_{2}}+\frac{P}{\psi_{2}}\left(\frac{x^{3}}{6}-\frac{x^{2}}{4} l\right) \\
& +\frac{7.496}{48 \psi_{2}} P l^{2} x-\frac{P l^{3}}{48 \psi_{2}} .
\end{aligned}
$$

(2) The deflection caused by the shear lag effect of the continuous composite box girders with CSWSB under the concentrated loads $w_{21}$ and $w_{22}$ was obtained as shown in the following equations:

$$
\text { When } 0 \leq x \leq \frac{l}{2} \xi_{1}(x)=\bar{n} P\left[a_{1} \operatorname{sh} k x+a_{2} \operatorname{ch} k x+\frac{0.312}{k^{2}}\right] \text {, }
$$

When $\frac{l}{2}<x \leq l, \xi_{2}(x)=\bar{n} P\left[a_{3} \operatorname{sh} k x+a_{4} \operatorname{ch} k x-\frac{0.688}{k^{2}}\right]$.

Using the boundary conditions: (1) $\left.\xi_{1}^{\prime}(x)\right|_{x=0}=0$; (2) $\left.\xi_{2}(x)\right|_{x=l}=0$; (3) $\left.\xi_{1}(x)\right|_{x=l / 2}=\left.\xi_{2}(x)\right|_{x=l / 2}$; and (4) $\left.\left(\xi_{1}^{\prime}(x)-\bar{n} M_{1}(x)\right)\right|^{l / 2}+\left.\left(\xi_{2}^{\prime}(x)-\bar{n} M_{2}(x)\right)\right|_{l / 2}=0$, the following equations are obtained:

$$
\begin{aligned}
& \xi_{1}(x)=\bar{n} P\left\{\left[-\frac{1}{k^{2}} \operatorname{ch} \frac{k l}{2}+\frac{1}{k^{2} \operatorname{chkl}}\left(\operatorname{sh} \frac{k l}{2} \operatorname{shkl}+0.688\right)\right] \operatorname{chkx}+\frac{0.312}{k^{2}}\right\}, \\
& \xi_{2}(x)=\bar{n} P\left[-\frac{1}{k^{2}} \operatorname{sh} \frac{k l}{2} \operatorname{sh} k x+\frac{1}{k^{2} \operatorname{chkl}}\left(\operatorname{sh} \frac{k l}{2} \operatorname{sh} k l+0.688\right) \operatorname{ch} k x-\frac{0.688}{k^{2}}\right] .
\end{aligned}
$$

Further, equations (34) and (35) were substituted into the equation of additional deflection due to shear lag effect and the following equations were obtained. By using the boundary conditions (1) when 
$x=0, \mathrm{w}_{21}=0$; (2) when $x=l / 2, w_{21}^{\prime}=w_{22}^{\prime}$; (3) when $x=l / 2, w_{21}=w_{22}$; and (4) when $x=l, w_{22}=0$, the following equations were deduced:

$$
\begin{aligned}
w_{21} & =\frac{\Psi_{3} \bar{n} P}{\Psi_{2} k^{3} \operatorname{ch} k l}\left[\operatorname{ch} \frac{k l}{2} \operatorname{sh} k x-0.688 \operatorname{sh} k x\right] \\
& -\frac{\psi_{3} \bar{n} P x}{2 \psi_{2} k^{2}}-\frac{\psi_{3} \bar{n} P x}{\psi_{2} k^{3} l \operatorname{ch} k l}\left[\operatorname{sh} \frac{k l}{2}-0.688 \operatorname{sh} k l\right] \\
w_{22}= & \frac{\Psi_{3} \bar{n} P}{\Psi_{2} k^{3} \operatorname{ch} k l}\left[\operatorname{sh} \frac{k l}{2} \operatorname{ch} k x(1-x)-0.688 \operatorname{sh} k x\right] \\
- & \frac{\psi_{3} \bar{n} P x}{2 \psi_{2} k^{2}}-\frac{\psi_{3} \bar{n} P x}{\psi_{2} k^{3} l \operatorname{ch} k l}\left[\operatorname{sh} \frac{k l}{2}-0.688 \operatorname{sh} k l\right]-\frac{\psi_{3} \bar{n} P l}{2 \psi_{2} k^{2}} .
\end{aligned}
$$

(3) The deflection caused by the shear deformation of the continuous composite box girders with CSWSB was obtained under the concentrated load $w_{3}$ and $Q^{\prime}(x)$ was found to be zero. By ignoring the contribution of the shear force to the curvature, the deflection $w_{3}$ due to the shear deformation of the two equal span continuous composite box girders under the concentrated load was calculated by one-time integral as follows:

$$
w_{3}=\int \frac{Q(x)}{G_{e} A_{w}} d x+D_{1} .
$$

When $0 \leq x \leq l / 2$, by boundary conditions when $x=0, w_{3}=0$, it can be deduced as shown in the following equation:

$$
w_{31}=\frac{0.312 P}{G_{e} A_{w}} x
$$

When $l / 2<x \leq l$, by boundary conditions when $x=1 / 2, w_{31}=w_{32}$, it can be deduced as shown in the following equation:

$$
w_{32}=-\frac{0.688 P}{G_{e} A_{w}} x+\frac{P l}{2 G_{e} A_{w}} .
$$

\subsection{Deflections of Two Equal Span Continuous Composite Box} Girders with CSWSB under Uniformly Distributed Load Condition. The schematic representation of two equal span continuous composite box girders with CSWSB is shown in Figure 4. According to equation (27) and the boundary conditions: when $x=0$ and $x=l$, the deflection values that were calculated using the elementary beam theory as well as those caused by the shear lag and the shear deformation were found to be zero, and they were calculated as follows:

(1) Deflection of the continuous composite box girders with CSWSB under uniformly distributed load $w_{1}$ is obtained as shown in the following equation:

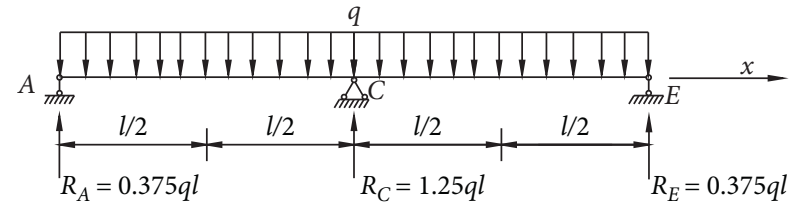

FIGURE 4: Schematic representation of two equal span continuous composite box girders with CSWSB under uniformly distributed load condition.

$$
w_{1}=-\frac{q}{24 \Psi_{2}}\left(\frac{3}{2} l x^{3}-x^{4}\right)+\frac{q l^{3}}{48 \Psi_{2}} x
$$

(2) Deflection due to the shear lag effect of continuous composite box girders with CSWSB under uniformly distributed load $\mathrm{w}_{2}$ is obtained as shown in the following equation:

$$
\begin{aligned}
w_{2} & =-\frac{\psi_{3} \bar{n} q}{\psi_{2} k^{2}}\left[-\frac{x^{2}}{2}+\frac{\operatorname{chkx}}{k^{2}}-\left(t h k l-\frac{5 k l}{8 \operatorname{chkl}}\right) \frac{\operatorname{sh} k x}{k^{2}}\right] \\
& +\frac{\psi_{3} \bar{n} q}{\psi_{2} k^{4}}+\frac{\psi_{3} \bar{n} q x}{\psi_{2} k^{2} l}\left[-\frac{l^{2}}{2}-\frac{1-\operatorname{chkl}}{k^{2}}-\left(\operatorname{thkl}-\frac{5 k l}{8 \operatorname{chkl}}\right) \frac{\operatorname{sh} k l}{k^{2}}\right] .
\end{aligned}
$$

(3) Deflection due to the shear deformation of continuous composite box girders with CSWSB under uniformly distributed load $w_{3}$ is obtained as shown in the following equation:

$$
w_{3}=-\frac{q}{2 G_{\mathrm{e}} A_{w}} x^{2}+\frac{q}{2 G_{\mathrm{e}} A_{w}} x l
$$

4.3. Deflections of the Simply Supported Composite Box Girders with CSWSB under Concentrated Load Condition. A simply supported composite box girder with CSWSB under concentrated load condition is shown in Figure 5. The deflection values of the simply supported composite box girders under concentrated load were calculated according to boundary conditions as follows:

(1) Theoretical deflections $\mathrm{w}_{11}$ and $w_{12}$ of the simply supported composite box girders with CSWSB under concentrated load were obtained as shown in the following equations:

When $0 \leq x \leq m, w_{11}=\frac{\zeta P x^{3}}{6 \psi_{2}}+\left[\frac{m p l}{3 \psi_{2}}+\frac{p m^{3}}{6 \psi_{2} l}+\frac{p m^{2}}{2 \psi_{2}}\right] x$

$$
\text { When } \begin{aligned}
m<x \leq l, w_{12}= & \frac{\eta P x^{3}}{6 \psi_{2}}-\frac{m P x^{2}}{2 \psi_{2}}+\left[\frac{\mathrm{pm}^{3}}{6 \psi_{2} l}+\frac{m p l}{3 \psi_{2}}\right] x \\
& -\frac{p m^{3}}{6 \psi_{2}} .
\end{aligned}
$$




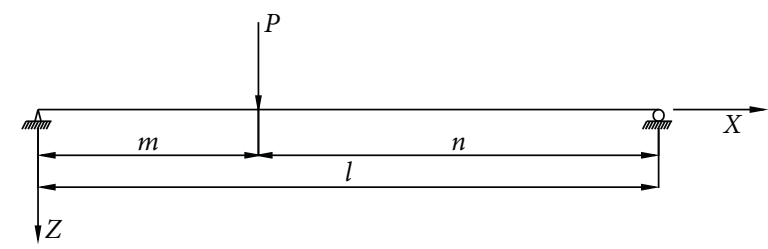

FIGURE 5: Schematic representation of a simply supported composite box girder with CSWSB under concentrated load condition.

(2) Deflections $w_{21}$ and $w_{22}$ caused by the shear lag effect of the simply supported composite box girders with
CSWSB under concentrated load were obtained as shown in the following equations:

$$
\begin{aligned}
& \text { When } 0 \leq x \leq m, w_{21}=\frac{\Psi_{3}}{\Psi_{2}} \bar{n} P\left(\frac{\operatorname{sh} k(l-m)}{k^{3} \operatorname{shkl}} \operatorname{shkx}\right)-\left[\frac{\Psi_{3} \bar{n} p}{\Psi_{2} k^{3}}-\frac{\Psi_{3} \bar{n} p m}{\Psi_{2} k^{2} l}\right] x \text {, }
\end{aligned}
$$

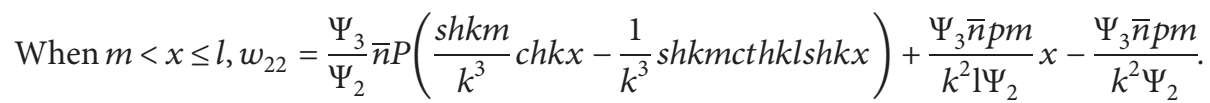

(3) Deflection $w_{3}$ caused by the shear deformation of simply supported composite box girders with CSWSB under concentrated load was obtained as shown in equations (48) and (49).

when $0 \leq x \leq m$, it can be deduced as

$$
\mathrm{w}_{31}=\frac{\zeta \mathrm{p}}{G_{e} A_{w}} x,
$$

when $m<x \leq l$, it can be deduced as

$$
w_{32}=\frac{-\eta p}{G_{e} A_{w}} x+\frac{\eta p l}{G_{e} A_{w}} .
$$

4.4. Deflections of Simply Supported Composite Box Girders with CSWSB under Uniformly Distributed Load Condition. The uniformly distributed load condition of a simply supported composite box girder with CSWSB is shown in Figure 6, and their deflection values under uniformly distributed load conditions were obtained as follows:

(1) Deflection $\mathrm{w}_{1}$ of the simply supported composite box girders with CSWSB under uniformly distributed load was obtained as shown in the following equation:

$$
w_{1}=-\frac{q}{24 \psi_{2}}\left(2 x^{3} l-x^{4}\right)+\frac{q l^{3}}{24 \psi_{2}} \text {. }
$$

(2) Deflection $w_{2}$ due to the shear lag effect of the simply supported composite box girders with CSWSB under uniformly distributed load conditions was obtained as shown in the following equation:

$$
\begin{aligned}
w_{2}= & \frac{\psi_{3} \bar{n} q}{\psi_{2} k^{2}}\left(\frac{\operatorname{chk} x}{k^{2}}+\frac{1-\operatorname{ch} k l}{k^{2} \operatorname{shkl}} \operatorname{shkx}-\frac{x^{2}}{2}\right) \\
& +\frac{\psi_{3} \bar{n} q l}{2 k^{2} \psi_{2}}+\frac{\psi_{3} \bar{n} q}{k^{4} \psi_{2}} .
\end{aligned}
$$

(3) Deflection $w_{3}$ of the simply supported composite box girders under uniformly distributed load was obtained as shown in the following equation:

$$
w_{1}=-\frac{q}{24 \psi_{2}}\left(2 x^{3} l-x^{4}\right)+\frac{q l^{3}}{24 \psi_{2}} .
$$

\section{An Example of the Deflection Analysis of the Composite Box Girders with CSWSB}

In this section, an example of the deflection analysis of the composite box girders with CSWSB and the influence of span width ratio on the deflection of the single box and a single cell simply supported composite box girders with CSWSB is illustrated.

5.1. Deflection Analysis of the Continuous Composite Box Girders with CSWSB with Single Box, Single Cell, and Two Equal Spans. The cross-section dimensions of the single box and single chamber model test beam (as shown in Figure 7) were designed according to the section size of $40 \mathrm{~m}$ span composite box girders with CSWSB bridges. They were determined by the Traffic Planning Institute and were reduced by the ratio of $1: 5$. C50 fine aggregate concrete was employed for the upper flange plate of the test beam concrete. The CSW and steel bottom plates were made of Q235 steel. For the Q235 steel plate, $E_{\mathrm{s}}$ was taken as $206 \mathrm{GPa}$ and vwas taken as 0.3 . Further, the ordinary steel bar was a grade I steel bar of $\varphi 6$. The span of the continuous composite box girder with CSWSB of single box and single cell is $(4+4) \mathrm{m}$. In this work, a total of 7 diaphragms were set. The diagram of half the upper flange and half the bottom plates of the single box and single chamber CSWSB model test beam is shown in Figure 8. The CSW plate thickness was taken as $4 \mathrm{~mm}$. The CSW structural diagram is shown in Figure 9, and a uniformly distributed loading diagram of the single box and 


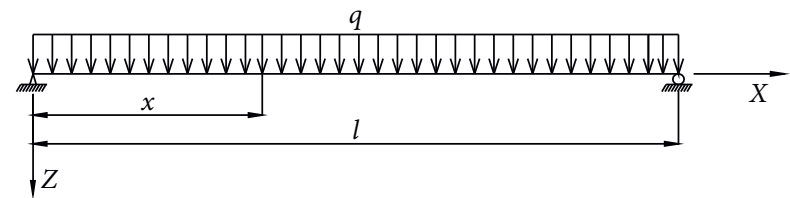

FIGURE 6: Schematic representation of a simply supported composite box girder with CSWSB under uniformly distributed load condition.

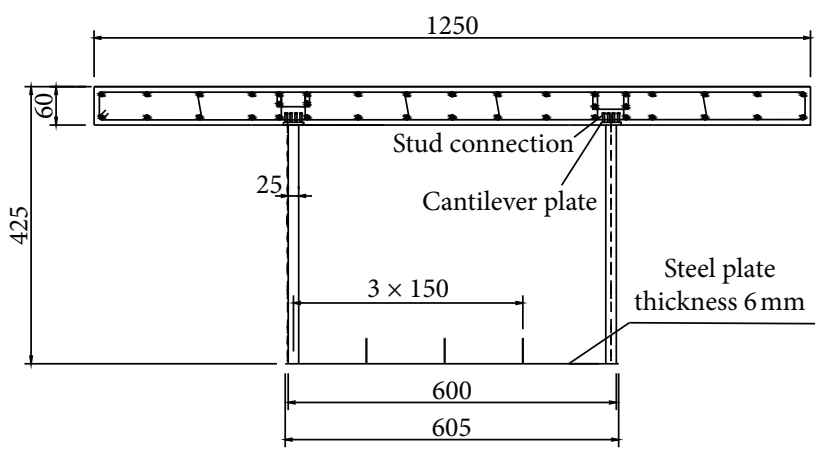

FiguRE 7: Unit cross-section of single box girder (unit: mm).

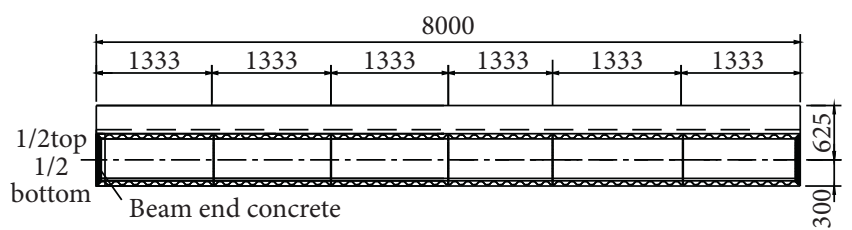

Figure 8: Diagram of half upper flange and half bottom plates of the single box and single chamber composite box girder with CSWSB (unit: $\mathrm{mm}$ ).

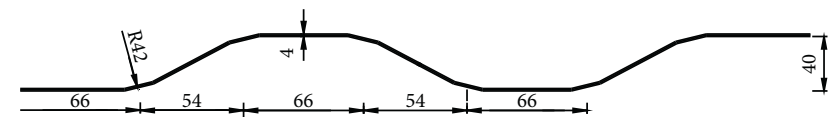

FIGURE 9: Structural diagram of corrugated steel web (unit: $\mathrm{mm}$ ).

single chamber continuous composite box girder is shown in Figure 10. The finite element model of the composite box girders with CSWSB was established using the ANSYS software. The solid element named solid 45 was applied for the simulation of the upper flange plate of the composite box girder, and the shell element named shell 63 was employed to simulate corrugated steel web, steel bottom plate, longitudinal rib, and diaphragm plate. In actual bridge structures, the CSW and steel bottom plates were welded and concrete upper flange plates were connected using shear keys. In the developed model, the shell and the solid elements shared the joint, and the master-slave node method was applied in order to establish the constraint equation connection. The finite element model of composite box girders with CSWSB with a single box and the single chamber is shown in Figure 11.

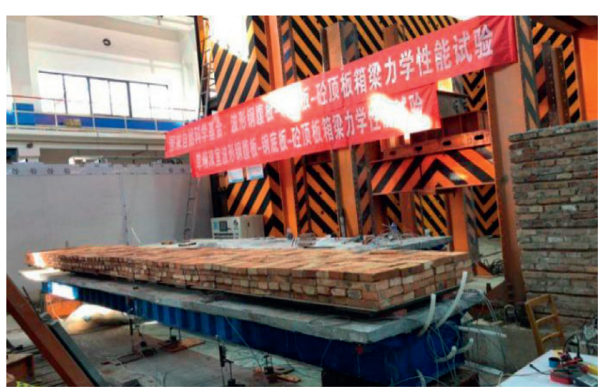

FIGURE 10: Uniform loading diagram of the single box and single cell continuous composite box girder with CSWSB.

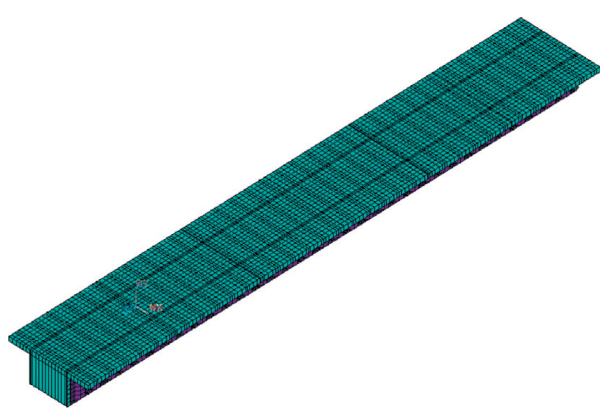

FIgURE 11: Finite element model of the single box and single cell composite box girder with CSWSB.

By considering the model of the two-span continuous composite box girder with CSWSB as an example, deflection values of the composite box girders were derived based on the deflection expressions under different loading modes. The deflection values that were obtained using the three methods are summarized in Table 1.

Under the action of the concentrated and the uniformly distributed loads in the middle of the two spans of the composite box girder, the deflection values obtained from four deflection measuring points in the midspan section of the composite box girder were processed and analyzed (i.e., the value of unloading value loading value bearing settlement is linearly interpolated into the midspan position), and the measured deflection value of the midspan section of the single box and single cell continuous composite box girder with CSWSB was obtained. Regardless of the application of the concentrated or uniformly distributed loading modes, the deflection value in the middle of the span was found to be relatively small when the beam was loaded to a maximum value and no failure feature was witnessed. Moreover, the test data were changed in the linear elastic range.

From Table 1, it is observed that the deflection values of the two equal span continuous composite box girders with CSWSB under different loading modes obtained using the derived deflection equation were in good agreement with measured values and those obtained from the finite element method, thus verifying the correctness of the developed deflection calculation equation under concentrated and uniformly distributed loading modes. When the two loading modes were applied separately, additional deflection due to the shear lag is found to account for less than $2 \%$ of the total 
TABLE 1: Midspan deflections of the single box and single cell continuous composite box girder with CSWSB (unit: mm).

\begin{tabular}{|c|c|c|c|c|c|c|c|}
\hline \multirow[b]{2}{*}{$\begin{array}{l}\text { Working } \\
\text { condition }\end{array}$} & \multirow[b]{2}{*}{$\begin{array}{c}\text { Load } \\
\text { amplitude }\end{array}$} & \multirow[b]{2}{*}{$\begin{array}{l}\text { Measured } \\
\text { value }\end{array}$} & \multicolumn{4}{|c|}{ Theoretical values calculated in this work } & \multirow[b]{2}{*}{$\begin{array}{c}\text { Finite } \\
\text { element } \\
\text { value }\end{array}$} \\
\hline & & & $\begin{array}{c}\text { Theoretical deflection } \\
\text { of primary beam }\end{array}$ & $\begin{array}{l}\text { Shear lag- } \\
\text { induced } \\
\text { deflection }\end{array}$ & $\begin{array}{l}\text { Shear deformation- } \\
\text { induced deflection }\end{array}$ & $\begin{array}{c}\text { Total } \\
\text { deflection }\end{array}$ & \\
\hline \multirow{4}{*}{$\begin{array}{l}\text { Concentrated } \\
\text { load }\end{array}$} & $8.35 \mathrm{kN}$ & 0.090 & 0.047 & 0.001 & 0.017 & 0.065 & 0.072 \\
\hline & $16.7 \mathrm{kN}$ & 0.144 & 0.093 & 0.002 & 0.034 & 0.129 & 0.144 \\
\hline & $30.7 \mathrm{kN}$ & 0.220 & 0.171 & 0.003 & 0.064 & 0.238 & 0.265 \\
\hline & $34.7 \mathrm{kN}$ & 0.274 & 0.194 & 0.003 & 0.072 & 0.269 & 0.289 \\
\hline \multirow{4}{*}{ Uniform load } & $0.549 \mathrm{kN} / \mathrm{m}$ & 0.026 & 0.007 & 0.000 & 0.003 & 0.010 & 0.013 \\
\hline & $2.636 \mathrm{kN} / \mathrm{m}$ & 0.058 & 0.034 & 0.001 & 0.018 & 0.053 & 0.065 \\
\hline & $4.724 \mathrm{kN} / \mathrm{m}$ & 0.108 & 0.061 & 0.001 & 0.031 & 0.093 & 0.116 \\
\hline & $8.224 \mathrm{kN} / \mathrm{m}$ & 0.175 & 0.105 & 0.002 & 0.055 & 0.162 & 0.182 \\
\hline
\end{tabular}

TABLE 2: Midspan deflections of the single box and single cell simply supported composite box girders with CSWSB (unit: mm).

\begin{tabular}{|c|c|c|c|c|c|c|c|}
\hline \multirow[b]{2}{*}{$\begin{array}{l}\text { Working } \\
\text { condition }\end{array}$} & \multirow[b]{2}{*}{$\begin{array}{l}\text { Load } \\
\text { amplitude }\end{array}$} & \multirow[b]{2}{*}{$\begin{array}{l}\text { Measured } \\
\text { value }\end{array}$} & \multicolumn{4}{|c|}{ Theoretical values calculated in this work } & \multirow[b]{2}{*}{$\begin{array}{c}\text { Finite } \\
\text { element } \\
\text { value }\end{array}$} \\
\hline & & & $\begin{array}{c}\text { Theoretical deflection } \\
\text { of primary beam }\end{array}$ & $\begin{array}{l}\text { Shear lag- } \\
\text { induced } \\
\text { deflection }\end{array}$ & $\begin{array}{l}\text { Shear deformation- } \\
\text { induced deflection }\end{array}$ & $\begin{array}{c}\text { Total } \\
\text { deflection }\end{array}$ & \\
\hline \multirow{4}{*}{$\begin{array}{l}\text { Concentrated } \\
\text { load }\end{array}$} & $17.6 \mathrm{kN}$ & 1.705 & 1.803 & 0.004 & 0.117 & 1.924 & 1.743 \\
\hline & $35.2 \mathrm{kN}$ & 3.325 & 3.606 & 0.008 & 0.234 & 3.848 & 3.485 \\
\hline & $63.2 \mathrm{kN}$ & 6.140 & 6.475 & 0.014 & 0.420 & 6.909 & 6.258 \\
\hline & $71.2 \mathrm{kN}$ & 7.405 & 7.294 & 0.016 & 0.474 & 7.784 & 7.498 \\
\hline \multirow{4}{*}{ Uniform load } & $2.250 \mathrm{kN} / \mathrm{m}$ & 1.330 & 1.152 & 0.002 & 0.061 & 1.215 & 1.342 \\
\hline & $3.938 \mathrm{kN} / \mathrm{m}$ & 2.225 & 2.017 & 0.004 & 0.105 & 2.126 & 2.349 \\
\hline & $5.625 \mathrm{kN} / \mathrm{m}$ & 3.185 & 2.882 & 0.005 & 0.151 & 3.036 & 3.356 \\
\hline & $7.500 \mathrm{kN} / \mathrm{m}$ & 4.335 & 3.842 & 0.007 & 0.199 & 4.048 & 4.474 \\
\hline
\end{tabular}

deflection. Under the condition of the application of concentrated load, the proportion of the additional deflection due to the shear deformation to the total deflection was found to be $26.9 \%$ and that caused by uniformly distributed loading was found to be $34 \%$. The results show that the deflection of two-span continuous CSWSB composite box girder changes linearly with the load value. For the ANSYS finite element model and the deflection calculation results of a continuous beam, the accuracy is found to be enough when small-amplitude bending occurs.

\subsection{Deflection Analysis of Single Box and Single Cell Simply} Supported Composite Box Girders with CSWSB. By considering the composite box girder with CSWSB with a single box and single cell as an example and continuous beam into a simply supported beam and by applying a concentrated or longitudinal uniformly distributed load to the whole beam, the midspan deflection value was obtained using the derived deflection expression. The results were compared with the values obtained using the ANSYS finite element method and the model test. The deflection values that were obtained using the three methods are presented in Table 2 and Figures 12 and 13 .

From Table 2 and Figures 12 and 13, it is observed that the deflection values of the simply supported composite box girders with CSWSB under different loading modes that were obtained using the derived deflection expression were in good agreement with the results obtained by the ANSYS finite element analysis and the measured values of the model test, thus verifying the correctness of the derived deflection calculation equations for simply supported composite box girders under concentrated or uniform distribution loading modes. Under concentrated load, the maximum ratio of additional deflections due to the shear lag and the shear deformation to total deflection was found to be $0.2 \%$ and $6.1 \%$, respectively. Under uniformly distributed loading, the maximum proportion of additional deflections caused by the shear lag and the shear deformation to total deflection was found to be $1.9 \%$ and $19 \%$, respectively. The results show that the deflection of the CSWSB composite box girder changes linearly with the load value. For the ANSYS finite element model and the deflection calculation results of the simply supported beam, the accuracy is found to be enough when small-amplitude bending occurs.

\subsection{Influence of Span Width Ratio on the Deflection of the} Single Box and Single Cell Simply Supported Composite Box Girders with CSWSB. The influence of the span width ratio on the deflection of the single box and single cell simply supported composite box girders with CSWSB under concentrated and uniformly distributed loading modes was calculated and analyzed. The concentrated load was $71.2 \mathrm{kN}$, and the uniform distribution load was $9.375 \mathrm{kN} / \mathrm{m}$. The calculation data are shown in Figures 14 and 15. 


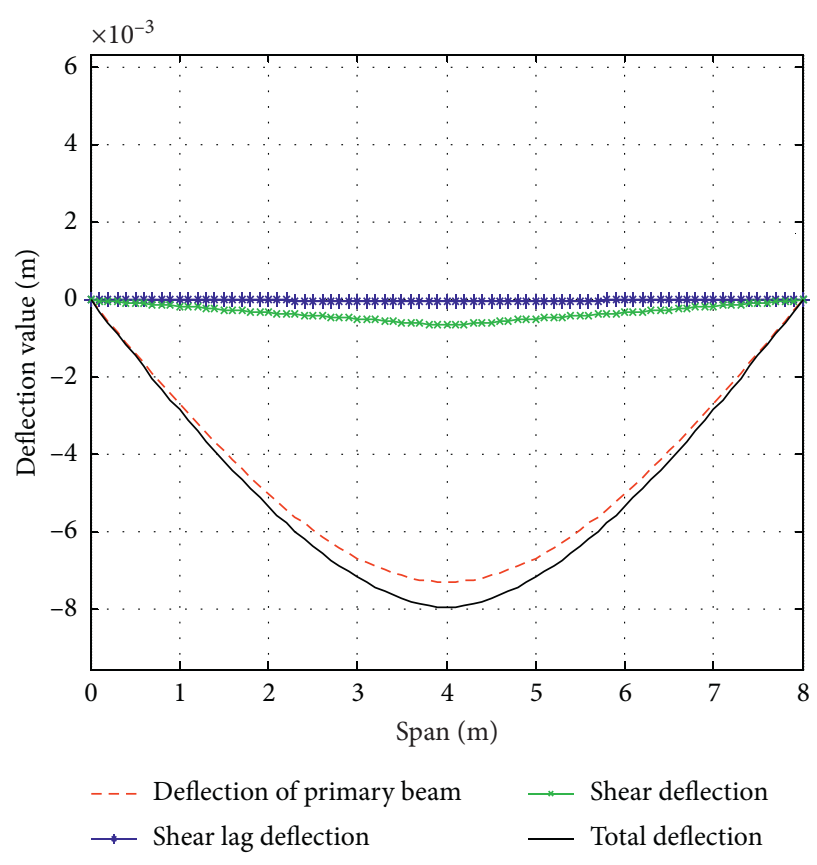

FIgURE 12: Concentrated load-deflection diagram of the single box and single cell simply supported composite box girder.

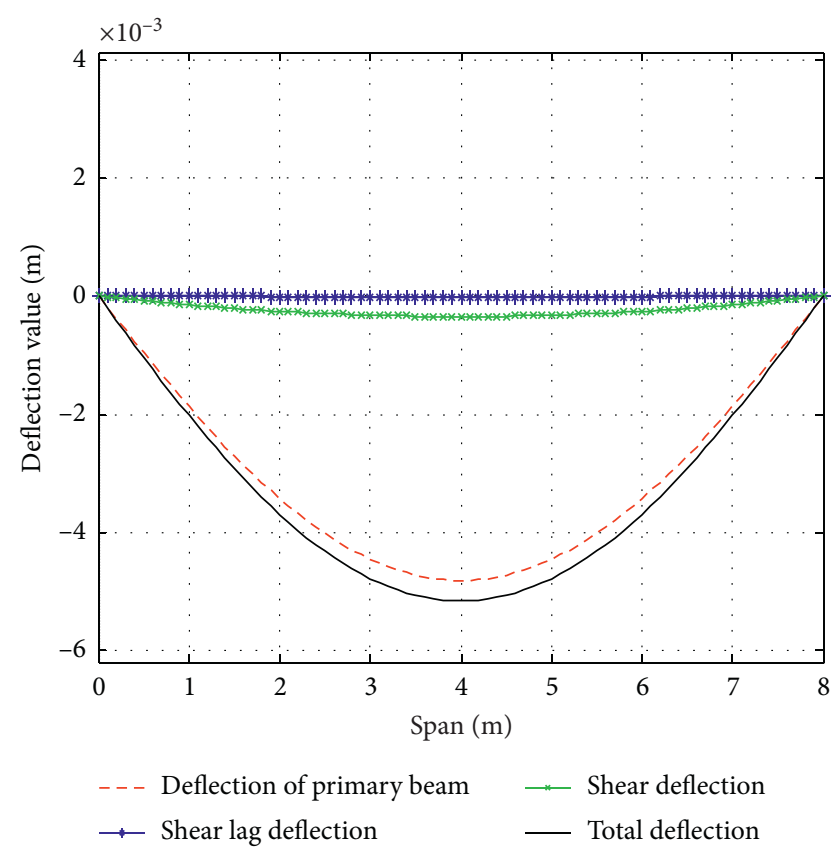

FIGURE 13: Uniform load-deflection diagram of the single box and single room simply supported composite box girder.

From Figures 14 and 15, it is observed that the ratio of the deflections that were induced by the shear lag and the shear deformation to the total deflection was gradually decreased with the increase in the span width ratio. When the span width ratio was equal to 1 , the maximum ratio of the deflection due to the shear lag to the total deflection was found to be $2.2 \%$, which is less than $5 \%$. Therefore, the shear force could be ignored in the calculation process. However, when

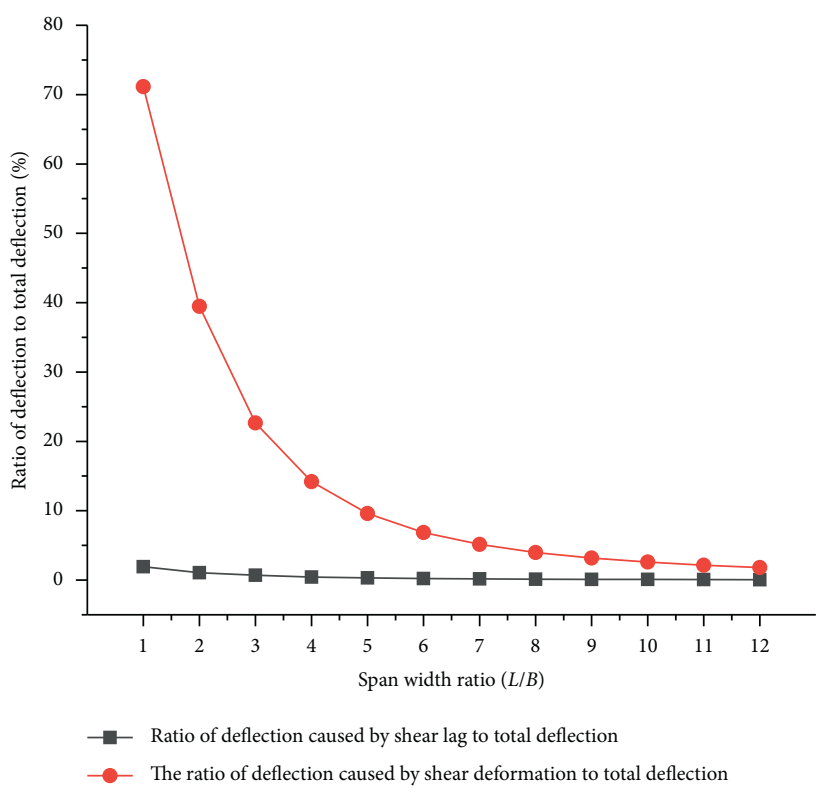

FIGURE 14: Influence of span width ratio on the deflection of the single box and single cell box girder under concentrated load condition.

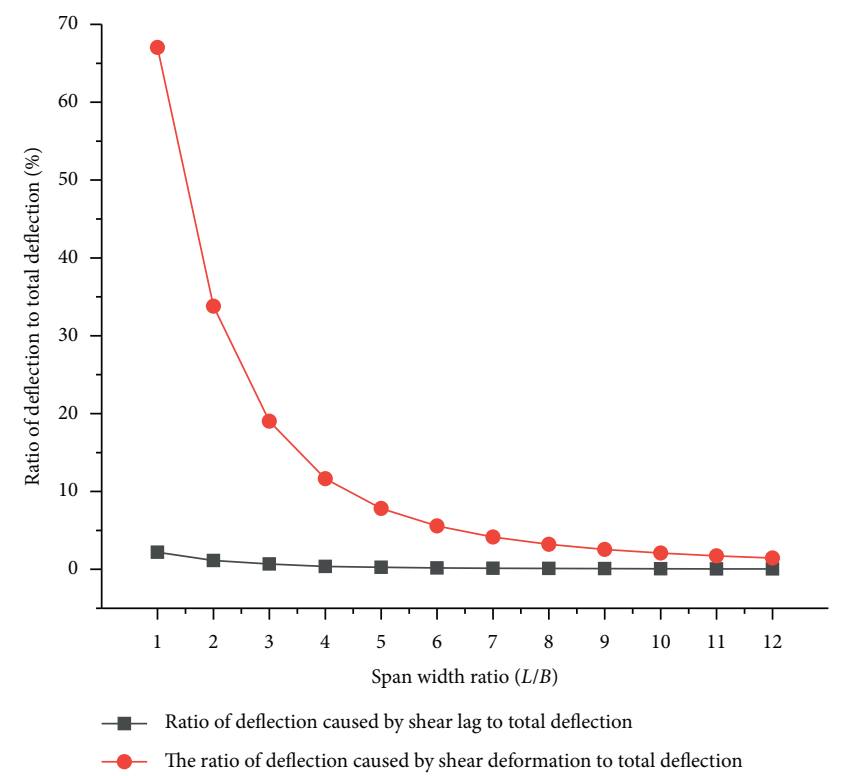

FIGURE 15: Influence of span width ratio on the deflection of the single box and single cell box girder under uniform distribution load condition.

the span width ratio was equal to 1 , the ratio of the shear deformation to the total deflection reached $71.15 \%$ while at the span width ratio of 8 , the proportion of the shear deformation deflection under concentrated load condition was decreased to $3.98 \%$. Further, the shear deformation under uniformly distributed load condition was found to be $3.22 \%$. For the single box and single cell composite box girders with CSWSB, the ratio of the shear deformation to the total deflection was found to be $71.15 \%$, and at span width ratios of equal to or greater than 8 , the deflection caused by the shear 
deformation could not be calculated. Therefore, in the calculation of the bridge deflection, the shear lag effect and the additional deflection caused by the shear deformation should be considered according to the span width ratio.

\section{Conclusion}

In this work, the following conclusions were obtained:

(1) The deflections that were caused by the shear lag and the shear deformation of the simply supported and continuous composite box girders with CSWSB under different loading conditions were calculated theoretically and were found to be in good agreement with the measured values of the model test and the ANSYS finite element values, thus verifying the correctness of the deflection calculation equations.

(2) For the single box and single cell simply supported and two-span continuous composite box girders with CSWSB, the additional deflection due to the shear lag accounted for less than $2 \%$ of the total deflection value, and therefore, it could be ignored in the deflection calculations. The deflection caused by the shear deformation accounted for $34 \%$ of the total deflection value, and the corresponding value under the uniformly distributed loading was higher than that under concentrated loading. Therefore, the shear deformation must be considered.

(3) The deflections that were caused by the shear lag and the shear deformation were gradually decreased with the increase in the span width ratio. When the span width ratio of the single box and single cell composite box girder with CSWSB was equal to or greater than 8 , the deflections caused by the shear lag and the shear deformation could be ignored.

(4) In the bridge finite element simulation, the ANSYS finite element model and the deflection calculation results established using the solid element and the shell element meet the calculation accuracy when the CSWSB composite box girder has small-amplitude bending. Further, in the theoretical calculation process of the bridge deflection, the shear lag effect and the additional deflection that were caused by the shear deformation are considered according to the span width ratio.

\section{Data Availability}

The data used to support the findings of this study are available from the corresponding author upon request.

\section{Conflicts of Interest}

The authors declare that they have no conflicts of interest.

\section{Acknowledgments}

This study was supported partially by two grants from the National Natural Science Foundation of China (grant nos. 51868040 and 51568036).

\section{References}

[1] Y. Chen, Design and Construction of Prestressed Concrete Bridge with Corrugated Steel Webs, China CommunicationsPress, Beijing, China, 2009.

[2] J.-Q. Guo, Z.-Z. Fang, and Z. Zheng, Design Theoryof Box Girder, China Communications Press, Beijing, China, 2008.

[3] J. Yi, H. Gilb, K. Youm et al., "Interactive shear buckling behavior of trapezoidally corrugated steel webs," Engineering Structures, vol. 3, no. 6, pp. 1659-1666, 2009.

[4] M. E. A.-H. Eldib, "Shear buckling strength and design of curved corrugated steel webs for bridges," Journal of Constructional Steel Research, vol. 65, no. 12, pp. 2129-2139, 2009.

[5] M. F. Hassanein and O. F. Kharoob, "Shear buckling behavior of tapered bridge girders with steel corrugated webs," Engineering Structures, vol. 74, no. 9, pp. 157-169, 2014.

[6] Li H. Jiang, J. S. Ye, S. Wan, and W. Q. Wu, "Influence of shear deformation on deflection of box girder with corrugated steel webs," Journal of Traffic and Transportation Engineering, vol. 2, no. 4, pp. 17-20, 2002.

[7] J.-G. Nie and F.-X. Li, "Theory model of corrugated steel web girder considering web shear behavior," China Journal of Highway and Transport, vol. 6, pp. 40-48, 2011.

[8] J.-G. Nie, F.-X. Li, and J.-S. Fan, "Effective stiffness method for calculating deflection of corrugated web girder," Engineering Mechanics, vol. 8, pp. 71-79, 2012.

[9] M. H. Li, S. Wan, Z. W. Jiang, and L. Ma, "Initial parameter method for deflection calculation of concrete composite girder with corrugated steel webs," Journal of South China University of Technology (Natural Science Edition), vol. 43, no. 2, pp. 66-74, 2015.

[10] W. qing Wu, S. Wan, J. S. Ye, and T. Y. Fang, "3-D finite element analysis of shear lag effect in composite box girder with corrugated steel webs," china Civil Engineering Journal, vol. 37, no. 9, pp. 31-36, 2004.

[11] Y. H. Zhang and L. X. Lin, "Shear lag analysis of thin-walled box girders adopting additional deflection as generalized displacement," Journal of Engineering Mechanics, vol. 140, no. 4, Article ID 04014005, 2014.

[12] B.-dong Liu, H.-W. Ren, and P.-F. Li, "Deflection analysis considering the characteristics ofBox girder with corrugated steel webs," China Railway Science, vol. 32, no. 3, pp. 21-26, 2011.

[13] Ji Wei, L. Shi-zhong, and L. Peng-zhen, "Deflection calculation and experimental study of PC composite box girder bridges with corrugated steel webs," Journal of Southwest Jiaotong University, vol. 52, no. 6, pp. 1-10, 2017.

[14] W. Ji, K. Luo, and J. Zhang, "Computation of deflections for PC box girder bridges with corrugated steel webs considering the effects of shear lag and shear deformation," Mathematical Problems in Engineering, vol. 7, Article ID 4282398, , 2020.

[15] C. Zhou, L. Li, and J. Wang, "Modified bar simulation method for shear lag analysis of non-prismatic composite box girders with corrugated steel webs," Thin-walled Structures, vol. 155, no. 10, Article ID 106957, 2020.

[16] Y. Chen, J. Dong, Z. Tong, R. Jiang, and Y. Yue, "Flexural behavior of composite box girders with corrugated steel webs and trusses," Engineering Structures, vol. 209, no. 4, Article ID 110275, 2020.

[17] Y. Chen, J. Dong, T. Xu, Y. Xiao, R. Jiang, and X. Nie, "The shear-lag effect of composite box girder bridges with corrugated steel webs and trusses," Engineering Structures, vol. 181, no. 2, pp. 617-628, 2019. 
[18] B. Zhang, W. Chen, and J. Xu, "Mechanical behavior of prefabricated composite box girders with corrugated steel webs under static loads," Journal of Bridge Engineering, vol. 23, no. 10, Article ID 04018077, 2018.

[19] M. Zhou, J. Zhang, J. Zhong, and Y. Zhao, "Shear stress calculation and distribution in variable cross sections of box girders with corrugated steel webs," Journal of Bridge Engineering, vol. 142, no. 6, Article ID 04016022, 2016.

[20] Y. L. Mo, C. H. Jeng, and H. Krawinkler, "Experimental studies of prestressed concrete box-girder bridges with corrugated steel webs , High Performance Materials in Bridges," pp. 209-218, 2003.

[21] Y. L. Mo, C. H. Jeng, and Y. S. Chang, "Torsional behavior ofprestressed concrete box-girder bridges with corrugated steelwebs," ACI Structural Journal, vol. 97, no. 6, pp. 849-859, 2000.

[22] S. Bao and J. Zhou, Structural Mechanics of Thin-Walled Members, China Construction Industry Press, Beijing, China, 2005.

[23] A. Samanta and M. Mukhopadhyay, "Finite element static and dynamic analyses of folded plates," Engineering Structures, vol. 21, no. 3, pp. 277-287, 1999. 